\title{
Revisiting Apoplastic Auxin Signaling Mediated by AUXIN BINDING PROTEIN 1
}

\author{
Mingxiao Feng, and Jae-Yean Kim*
}

\begin{abstract}
It has been suggested that AUXIN BINDING PROTEIN 1 (ABP1) functions as an apoplastic auxin receptor, and is known to be involved in the post-transcriptional process, and largely independent of the already well-known SKP. cullin-F-box-transport inhibitor response (TIR1) /auxin signaling $F$-box (AFB) $\left(S C F^{\pi R 1^{1 / A F B}}\right)$ pathway. In the past 10 years, several key components downstream of ABP1 have been reported. After perceiving the auxin signal, ABP1 interacts, directly or indirectly, with plasma membrane (PM)-localized transmembrane proteins, transmembrane kinase (TMK) or SPIKE1 (SPK1), or other unidentified proteins, which transfer the signal into the cell to the Rho of plants (ROP). ROPs interact with their effectors, such as the ROP interactive CRIB motif-containing protein (RIC), to regulate the endocytosis/exocytosis of the auxin efflux carrier PIN-FORMED (PIN) proteins to mediate polar auxin transport across the PM. Additionally, ABP1 is a negative regulator of the traditional SCF ${ }^{T R 1 / A F B}$ auxin signaling pathway. However, Gao et al. (2015) very recently reported that $A B P 1$ is not a key component in auxin signaling, and the famous abp1-1 and abp1-5 mutant Arabidopsis lines are being called into question because of possible additional mutantion sites, making it necessary to reevaluate ABP1. In this review, we will provide a brief overview of the history of $A B P 1$ research.
\end{abstract}

\section{INTRODUCTION}

The hormone auxin regulates many aspects of plant growth and development in all life stages, so studying the molecular and genetic mechanisms of the auxin signaling pathways is important for understanding plant growth and development. To perceive the presence of this hormone, auxin receptors are required, and they play a critical role as the "vanguard" for auxin signaling pathway. Two different classes of auxin receptors

Division of Applied Life Science (BK21plus program), Plant Molecular Biology and Biotechnology Research Center, Gyeongsang National University, Jinju 660-701, Korea

*Correspondence: kimjy@gnu.ac.kr

Received 20 July, 2015; revised 4 October, 2015; accepted 5 October, 2015; published online 15 October, 2015

Keywords: $\mathrm{ABP}$, apoplastic signaling, auxin, auxin binding, hormone receptor have been found in plants: the TIR1/AFB and AUXIN/ INDOLE-3-ACETIC ACID (AUX/IAA) co-receptors, which control the auxin-dependent transcriptional responses, and AUXIN BINDING PROTEIN 1 (ABP1) (Tromas et al., 2013). ABP1 has been known and studied for almost 40 years, but due to the lack of available abp1 mutants, the first two decades of research were focused on its molecular and biochemical nature, e.g., the study of auxin binding (Jones 1994; Woo et al., 2002). During that time, the subcellular localization of ABP1 puzzled many researchers due to obvious contradiction presented by the localization of its endoplasmic reticulum (ER) and its apoplast-based function (Barbier-Brygoo et al., 1991; Inohara et al., 1989; Jones and Herman, 1993; Tillmann et al., 1989). To this day, its mechanism of escape from the ER is still being studied (Xu et al., 2014) and not known in detail. In 2001, the first $A B P 1$ mutant (abp1-1) was identified from Arabidopsis (Chen et al., 2001), which shed light on the long sought ABP1 signaling mechanism. Since then, several mutant lines have been generated and studied intensely, resulting in the identification of several key ABP1 downstream components, such as ROP6-RIC1 and ROP2-RIC4. But recently there were several findings that shake the whole established $A B P 1$ signaling world, mainly from the identification of two $A B P 1$ null mutants which had no any auxin-related phenotypes (Gao et al., 2015), and the speculation of other mutation sites from abp1-1 (Habets and Offringa, 2015) and abp15 (Ender et al., 2015), another Arabidopsis mutant line which was usually used by ABP1 studies. In this review, the recent findings and remaining questions regarding the study of ABP1 will also be summarized and discussed.

\section{NATURE OF ABP1}

\section{Identification of ABP1}

In 1972, auxin was shown to bind to particulate cell fractions, potentially to a protein from maize coleoptiles (Cross and Briggs, 1978; Hertel et al., 1972). Later, auxin-binding proteins (ABPs) were successfully identified from maize through either indirect methods, such as the immunological approach (Löbler and Klämbt, 1985) and $\mathrm{Ca}^{2+}$-promoted sedimentation (Shimomura et al., 1986), or direct methods, such as photoaffinity labeling (Jones and Venis, 1989). Maize ABP1 has a 603-base pair open reading frame that codes a $22 \mathrm{kDa}$ protein; a signal peptide of 38 amino acids, which was expected to translocate ABP1 across the ER membrane; and a C-terminal KDEL sequence, which was thought to be a signal for ER lumen 
retention (Inohara et al., 1989; Tillmann et al., 1989).

The transgenic production of the model plant Arabidopsis thaliana is much easier than for maize, so to perform complementation analysis of ABP-related mutants, it was necessary to identify ABP from Arabidopsis. In 1992, Arabidopsis ABP1 (AT4G02980), the sole ABP gene in Arabidopsis, was identified, which is similar to its maize homolog, i.e., $22 \mathrm{kDa}$ molecular mass, N-terminal signal peptide of 33 amino acids, and $\mathrm{C}$ terminal KDEL sequence (Palme et al., 1992).

\section{Interaction between ABP1 and auxin}

At the time that $A B P 1$ was sequenced, the relative changes in auxin responsiveness and the concentration of $A B P 1$ were found to be correlated (Jones et al., 1989). An antibody against a short sequence of maize ABP1 (Arg-Thr-Pro-lle-His-Arg-HisSer-Cys-Glu-Glu-Val-Phe-Thr) was found to have an auxin-like function in hyperpolarizing the protoplast transmembrane potential (Venis et al., 1992), indicating that this region is essential for the binding of ABP with auxin. Together with the KDEL sequence, this region, which was later called Box $A$ (Brown and Jones, 1994), is shared by all of the ABPs that have been identified from plants (Napier et al. 2002).

ABP1 can bind with auxin under physiological concentrations suitable for the activities of this hormone, and the ideal $\mathrm{pH}$ for binding is 5.0-6.0 (reviewed by Bertoša et al., 2008; Napier et al., 2002). The correlation between the growth-promoting effects of auxin and its binding affinity to purified ABP1 was also measured (Rescher et al., 1996), and the crystal structure of maize ABP1 was determined, which is a dimer as it is found in solution (Shimoura et al., 1986; Woo et al., 2002). Residues 26148 fold into a $\beta$-jellyroll barrel formed by two antiparallel $\beta$ sheets, and the auxin binding pocket is deep and predominantly hydrophobic with a zinc ion at the bottom of the pocket. When auxin binds within the pocket, its charged carboxylate group binds the zinc, and its aromatic ring binds the hydrophobic residues (Woo et al., 2002). Two conformations can be adopted by ABP1. When the auxin is absent, the extended Cterminus of ABP1 is irregular in structure except for a short $\alpha$ helix (residues 152-160) (Woo et al., 2002), and tryptophan 151 is pulled out from the binding site (Bertoša et al., 2008). However, binding with auxin induces tryptophan 151 to interact with the aromatic auxin group, and the C-terminus is not extended, resulting in a more rigid conformation (Bertoša et al., 2008). Because of the single disulfide between Cys2 and Cys155, the $\mathrm{N}$-terminal extension (residues 1-25), which is also irregular apart from a short $\beta$-strand, might also be rearranged by the binding (Woo et al., 2002). The change in conformation between the auxin-free and auxin-binding forms could be the signal that induces the transmembrane ABP1 receptor protein to transfer the auxin signal into the cell.

\section{ABP1 localization puzzle}

In animal cells, the KDEL retention sequence is sufficient for retention in the ER lumen (Pelham, 1989), and for ABP1, the presence of both the signal peptide and the KDEL sequence indicate its localization in the ER. Indeed, more than $90 \%$ of maize ABP1 was shown to be localized in the ER (Jones and Herman, 1993). However, maize ABP1 could not be photolabeled to auxin in intact cells, and at the $\mathrm{pH}$ level of the ER lumen, its binding with auxin was not detectable (Tian et al., 1995). Additionally, an antibody against maize ABP1 could block the auxin-induced hyperpolarization of the plasma membrane (PM) of tobacco mesophyll protoplasts, and adding maize ABP1 to a medium bathing tobacco protoplasts enhanced the auxin effect (Barbier-Brygoo et al., 1991; Jones and Her- man, 1993). These results indicated the possibility of the presence of ABP1 on the apoplast and PM, and the results of electron microscopic immunocytochemistry finally indicated that maize ABP1 could escape from the ER to the cell wall via the secretory system (Jones and Herman, 1993), proving that ABP1 and auxin act at the cell surface. By using immunogold histochemistry together with transmission electron microscopy and epifluorescence microscopy of ABP1-GFP, it was shown that approximately $22 \%$ of Arabidopsis ABP1 was secreted from the ER to the apoplast (Xu et al., 2014), but ABP1 has no transmembrane domain to anchor itself into the PM. The ABP1 C-terminal sequence can bind with a glycosylphosphatidylinositol (GPI)-anchored protein designated as C-terminal peptidebinding protein 1 (CBP1), which may inactivate the KDEL sequence to facilitate the escape of ABP1 from the ER, and the phospholipid tail of CBP1 may serve as an anchor to the PM (Paulick and Bertozzi, 2008; Shimomura, 2006; Tromas et al., 2010). Xu et al. (2014) identified the PM-localized transmembrane kinases (TMKs), which bind with ABP1 to transduce the auxin signal, but it is still not known if TMK itself can serve as the anchor for all of the ABP1 molecules. The exact mechanism of $A B P 1$ escape and anchoring remains unknown.

\section{ABP1 SIGNALING PATHWAY}

\section{Available ABP1 mutants}

To study gene function, mutant lines are required, and to date, ABP1 mutants have been generated and studied by many groups (Table 1). Using these mutants, it is finally possible to elucidate the role that $\mathrm{ABP} 1$ performs in auxin pathway, but two newly-identified ABP1-null mutants, abp1-c1 and abp1-TD1, do not have any previously reported auxin-related phenotypes (Gao et al., 2015). This calls into question whether ABP1 is really an auxin receptor. Several explanations have been proposed: the previously identified abp1 mutants might be subject to off-target effects (Gao et al., 2015; Grones et al., 2015; Liu 2015), and the new abp1-c1 and abp1-TD1 may express undetectable levels of functional mutant ABP1 protein by either an alternative splicing or the expression of a truncated transcript (Habets and Offringa, 2015). Embryo lethal abp1-1 mutant might contain background mutations (Enders et al., 2015; Habets and Offringa, 2015; Liu, 2015) that mask the function of other auxin signaling components. The T-DNA insertion in embryo-lethal abp1-1 may influence the upstream BELAYA SMERT/RUGOSA2 (BSM/RUG2) gene because the bsm mutant allele is also embryo-lethal (Habets and Offringa, 2015), and this is supported by the negative result in the complementation assay by $A B P 1$ expression (Grones et al., 2015). These findings undermine the data got from $a b p 1-1$ and $a b p 1-5$, but fail to explain the auxin-related phenotype of down-regulated mutants such as SS12S, SS12K and abp1-AS.

Usually, that knockout a gene has no resulting phenotypes in Arabidopsis would be because there are other proteins functionally overlapping with it. This might also apply to ABP1, after the finding that new $A B P 1$ null mutants have no phenotype and old $A B P 1$ mutants are being suspected. It is quite possible that there are some other proteins that functionally overlap with ABP1. Regarding SS12S, SS12K and abp1-AS, they were raised from immunization and $\mathrm{RNAi}$ in Col-0 background (Braun et al., 2008), and the antibody and antisense RNA raised against $A B P 1$ may also inhibit other auxin binding proteins with overlapping function with ABP1. Most recently, also in Col-0 background, the overexpression of $A B P 1$ caused gain-offunction auxin-related phenotypes, which could be masked by point-mutations targeting the auxin-binding site of ABP1, sup- 
Table 1. abp1 mutants and ABP1 overexpression or inducible lines

\begin{tabular}{|c|c|c|c|c|}
\hline Line name & $\begin{array}{l}\text { Transgenic } \\
\text { plant }\end{array}$ & $\begin{array}{l}\text { Cell } \\
\text { line/Plant } \\
\text { line }\end{array}$ & Type & Used in studies (Representative) \\
\hline F652; F631 & Tobacco & Cell line & Overexpression & Jones et al., 1998 \\
\hline MJ10B & Tobacco & Plant line & Overexpression & Jones et al., 1998 \\
\hline $\begin{array}{l}\text { KDEL; HDEL; KEQL; } \\
\text { KDELGL }\end{array}$ & Tobacco & Plant line & Overexpression & Bauly et al., 2000 \\
\hline abp $1-1$ & Arabidopsis & Plant line & $\begin{array}{l}\text { Knockout } \\
\text { (T-DNA insertion) }\end{array}$ & Chen et al., 2001; Effendi et al., 2013; 2015 \\
\hline NAS1 & Tobacco & $\begin{array}{l}\text { Cell line } \\
\text { (BY-2) }\end{array}$ & $\begin{array}{l}\text { Downregulation } \\
\text { (RNAi) }\end{array}$ & Chen et al., 2001 \\
\hline SS12S; SS12K & Tobacco & $\begin{array}{l}\text { Cell line } \\
\text { (BY-2) }\end{array}$ & $\begin{array}{l}\text { Downregulation } \\
\text { (Immunization) }\end{array}$ & David et al., 2007 \\
\hline SS12S; SS12K & Arabidopsis & Plant line & $\begin{array}{l}\text { Downregulation } \\
\text { (Immunization) }\end{array}$ & $\begin{array}{l}\text { Braun et al., 2008; Chen et al., 2012; 2014; Pa- } \\
\text { que et al., 2014; Tromas et al., 2009; Xu et al., } \\
\text { 2010; }\end{array}$ \\
\hline $\begin{array}{l}\text { AS9/ABP1AS/abp1- } \\
\text { AS }\end{array}$ & Arabidopsis & Plant line & $\begin{array}{l}\text { Downregulation } \\
\text { (RNAi) }\end{array}$ & $\begin{array}{c}\text { Braun et al., 2008; Paque et al., 2014; Tromas et } \\
\text { al., 2009; Xu et al., } 2010\end{array}$ \\
\hline abp1-5 & Arabidopsis & Plant line & $\begin{array}{l}\text { His94->Tyr } \\
\text { missense mutation }\end{array}$ & $\begin{array}{l}\text { Effendi et al., 2013; Robert et al., 2010; Xu et al., } \\
\qquad 2010 ; 2014\end{array}$ \\
\hline$A B P 1-G F P$ & Arabidopsis & Plant line & Overexpression & Chen et al., 2014; Robert et al., 2010 \\
\hline $\begin{array}{l}A B P 1^{\triangle K D E L}-G F P \\
A B P 1-5^{\triangle K D E L}-G F P\end{array}$ & Arabidopsis & Plant line & Overexpression & Robert et al., 2010 \\
\hline$a b p 1 / A B P 1$ & Arabidopsis & Plant line & Downregulation & Effendi et al., 2011 \\
\hline$a b p 1-c 1$ & Araidopsis & Plant line & $\begin{array}{l}\text { Loss-of-function } \\
\text { (CRISPR) }\end{array}$ & Gao et al., 2015 \\
\hline$a b p 1-T D 1$ & Arabidopsis & Plant line & $\begin{array}{l}\text { Knockout } \\
\text { (T-DNA insertion) }\end{array}$ & Gao et al., 2015 \\
\hline $\begin{array}{ll}A B P 1-H 59 A ; & A B P 1- \\
H 59 A / H 61 A ; & A B P 1-\end{array}$ & Arabidopsis & Plant line & Point-mutation & Grones et al., 2015 \\
\hline $\begin{array}{l}R 24 K ; \quad A B P 1-L 27 V ; \\
A B P 1-Q 48 D ; \quad A B P 1-\end{array}$ & & & & \\
\hline T56V; $\quad$ ABP1-P57L; & & & & \\
\hline ABP1-F148L; $\quad$ ABP1- & & & & \\
\hline W152Y; & & & & \\
\hline$R 24 K / L 27 V$ & & & & \\
\hline T56V/P57L; $\quad$ ABP1- & & & & \\
\hline F148L/W152Y; ABP1- & & & & \\
\hline $\begin{array}{l}\text { V66A; ABP1-F92L; } \\
\text { ABP1-P103L; ABP1- } \\
\text { Q155D }\end{array}$ & & & & \\
\hline
\end{tabular}

porting the important role of $\mathrm{ABP} 1$ in auxin-mediated processes (Grones et al., 2015). It is possible that the overexpressed mutated ABP1 may occupy the binding site in SPK1 or TMK, preventing the wild type $A B P 1$ from binding with them. Alternatively, the mutated ABP1 may form complexes with the wild type $A B P 1$ or the functional homologues thus masking their function, since ABP1 has been known to form dimers to perform their function (Woo et al., 2002). This indicates that there may be other proteins functionally overlapping with ABP1 in Arabidopsis.

\section{ABP1 signaling in leaves}

It has long been reported that ABP1 is involved in leaf development. Overexpression of $A B P 1$ in tobacco resulted in leaves with larger cells (Jones et al., 1998), and ABP1 repression in Arabidopsis caused severe epinasty, smaller epidermal cells, smaller surface area, a slower growth rate and a reduced number of epidermal cells (Braun et al., 2008). Additionally, both abp1-5, which contains a His94 $\rightarrow$ Tyr missense mutation in the putative auxin-binding region, and the abp1-AS line showed reduced lobe formation that could not be rescued with an ex- ogenous auxin treatment (Xu et al., 2010), implying that the leaf defects are the result of blocking the auxin signaling. Although abp1-5 is not $100 \%$ reliable because of additional mutation sites (Enders et al., 2015), but the pavement cell phenotypes were also got both from abp1-AS (Xu et al., 2010), from other newly-generated $A B P 1$ mutant lines (Effendi et al., 2015), and from $A B P 1$ overexpressing lines generated from Col-0 (Grones et al., 2015). Therefore the leaf pavement cell phenotypes seems indeed due to deviant expression of $A B P 1$. The same phenotype has been observed from the yuc1 yuc2 yuc4 yuc6 quadruple mutant, which presents defective auxin biosynthesis (Xu et al., 2010). Interestingly, the rop2RNAi rop4-1 mutant and the pin1-1 mutant have also shown the same phenotype, which cannot be rescued by exogenous auxin (Xu et al., 2010), indicating that $A B P 1, R O P 2 / 4$, and PIN1 are involved in the same auxin signaling pathway required for normal leaf lobe development (Fig. 1). Furthermore, ABP1-mediated auxin signaling is related to the auxin-involved indentation process that requires ROP6 function (Xu et al., 2014).

PIN proteins mediate polar auxin transport by modulating 


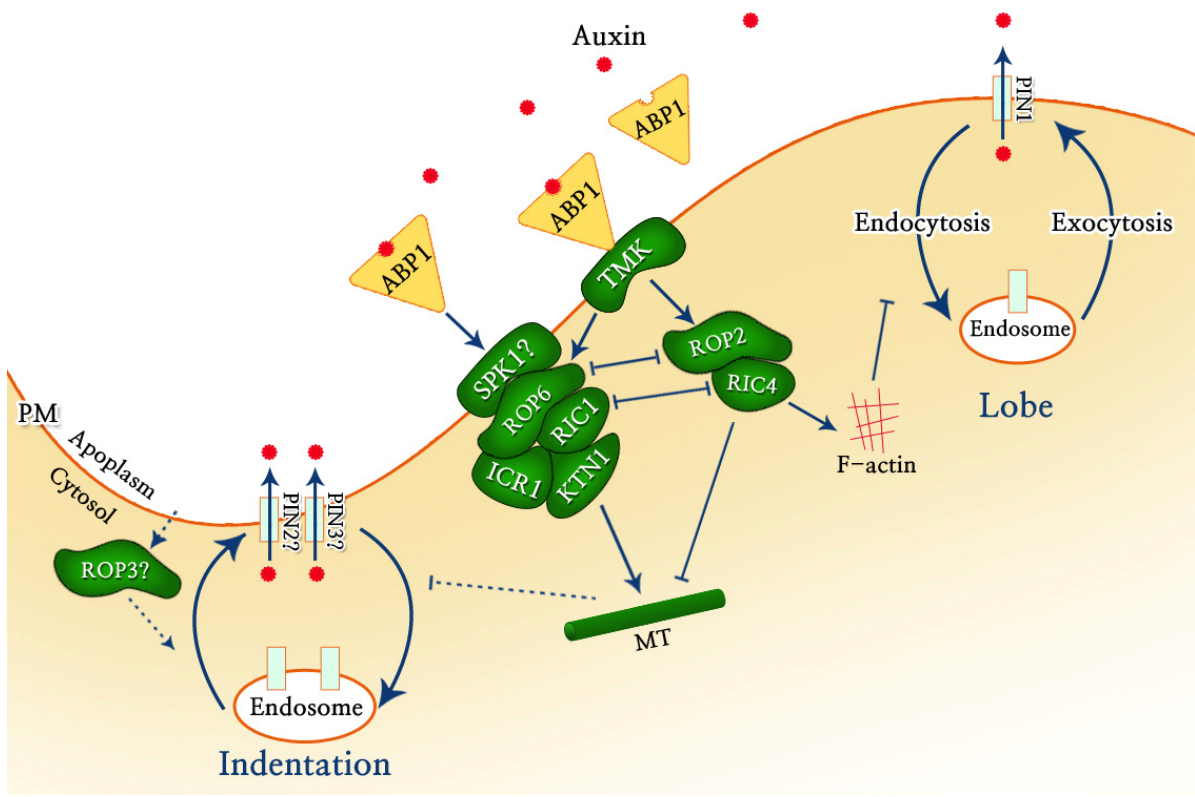

Fig. 1. $\mathrm{ABP} 1$ signaling pathway in leaf pavement cells. In leaf pavement cells, auxin in the apoplast is sensed by secreted ABP1, which binds to its PM-localized receptor, TMK, to activate two intertangled downstream pathways: ROP2RIC4 and ROP6-RIC1. The former contributes to lobe outgrowth through the stabilization of cortical actin microfilaments, which suppresses PIN2 endocytosis; the latter, via KTN1, inhibits indentation outgrowth through the reorganization of cortical TMs, which suppresses the endocytosis of PIN1 and possibly other PINs as well. SPK1 may also contribute to the ROP6-RIC1 pathway as it does in the root. Dotted lines and question marks indicate potential signaling and signaling components, respectively. their endocytosis, which is critical for plant development (Lin et al., 2012), and ROP2, through its effector protein RIC4, accumulates cortical actin microfilaments, which further inhibits the endocytosis of PIN1 (Nagawa et al., 2012). ROP6 binds and activates cortical microtubule (MT)-associated RIC1 (Fu et al., 2009), which subsequently activates the MT-severing protein katanin (KTN1) to promote MT ordering (Lin et al., 2013). Such events do not involve de novo PIN protein synthesis but a transcytosis-like mechanism that acts from one cell side to another to rapidly change polarity and concomitantly redirect auxin flow (Tejos and Friml, 2012).

However, neither ABP1 nor ROPs have a transmembrane domain, so a transmembrane protein is expected to transfer the signal from apoplastic ABP1 to cytoplasmic ROP (Xu et al., 2010). Very recently, TMK members of the receptor-like kinase family were found by Co-IP to interact with ABP1 to promote ROP2 and ROP6 activities (Fig. 1) (Xu et al., 2014), integrating TMK as the long-sought transmembrane ABP1 receptor into its signaling pathway. This is supported by which tmk1,2,3,4 mutant lines exhibits the leaf pavement cell lobe phenotype similar to that of abp1 and rop mutants.

Another ABP1 transmembrane receptor candidate is SPK1 (SPIKE1). Similar to rop6, ric1, ktn (Lin et al., 2013), abp1-5, and abp1-AS (Xu et al., 2010), the spk1 mutant presents greater indentation length and reduced lobe number (Lin et al., 2012; Qiu et al., 2002), indicating that SPK1 may also have a role in ABP1 signaling during the development of leaf pavement cells. Additionally, SPK1 directly binds ROP6, which acts downstream of ABP1 (Chen et al., 2012; Lin et al., 2012). In the root, the SPK1-regulated ROP6-RIC1 system regulates PIN1 and PIN2 internalization/endocytosis (Chen et al., 2012; Lin et al., 2012), and ROP3 is required to recycle PIN1 and PIN3 back to the PM (Huang et al., 2014). It is possible that SPK1 regulates PIN1 through the interactions between the ROP2-RIC4 and ROP6-RIC1 systems (Grones and Friml, 2015; Miyawaki and Yang, 2014). However, there has been no report of the function of ROP3, PIN2 and PIN3 in the leaf to date, and it is also unknown whether their mutants have pavement cell defects. For further study, it would be interesting to study the leaf phenotypes of the pin2 and pin3 mutants to determine the role of SPK1, PIN2 and PIN3 in ABP1 signaling in the leaf cell.

\section{$A B P 1$ signaling in roots}

Soon after $A B P 1$ knockdown Arabidopsis lines were generated, it was found that knockdown of this gene (line ABP1-AS, SS12K and SS12S) caused a drastic reduction in root growth $(60-80 \%)$, and the size of the root meristem was reduced to one-third compared to the wild type (Tromas et al., 2009). Other phenotypes, such as greater root slanting angle and tropism defects, were also observed from heterozygous abp1-1 line (Effendi et al., 2011; 2015). The D-type CYCLIN/ RETINOBLASTOMA (RBP) pathway, which is known to control G1/S transition during cell division (de Jager et al., 2009), and PLETHORA (PLT), which is required for root stem cell maintenance (Galinha et al., 2007), were found acting downstream of ABP1 in root (Tromas et al., 2009).

However, unlike in leaf pavement cell, no transmembrane protein has yet been found from root that directly interacts with ABP1. Instead, SPK1, a transmembrane protein, was proposed to interact with an inactive form of ROP6 (Fig. 2) (Lin et al., 2012). Compared to the leaf pavement cell, the root requires higher auxin concentrations to inhibit endocytosis, and the ROP6-RIC1 pathway inhibits PIN2 internalization through the stabilization of actin filaments instead of microtubules (Lin et al., 2012). However, how the leaf MT regulator RIC1 affects the dynamics of actin in the root remains unclear (Nagawa and Yang, 2014). The ROP6 effector RIC1 also interacts with the conserved MT-severing protein katanin (KTN1) to promote MT reorientation (Chen et al., 2014), but how this activity is involved in PIN endocytosis isunclear. The function of ROP3 in regulating the recycling of PIN1 and PIN3 back to the PM was recently studied (Huang et al., 2014), and interestingly, ROP3 was also required to maintain PLT1/PLT2 expression (Huang et al., 2014), which is consistent with a previous study (Tromas et al., 2009) and suggests that ABP1 may regulate the identity of root stem cells through ROP3. Gain-of-function of ROP6 increases 


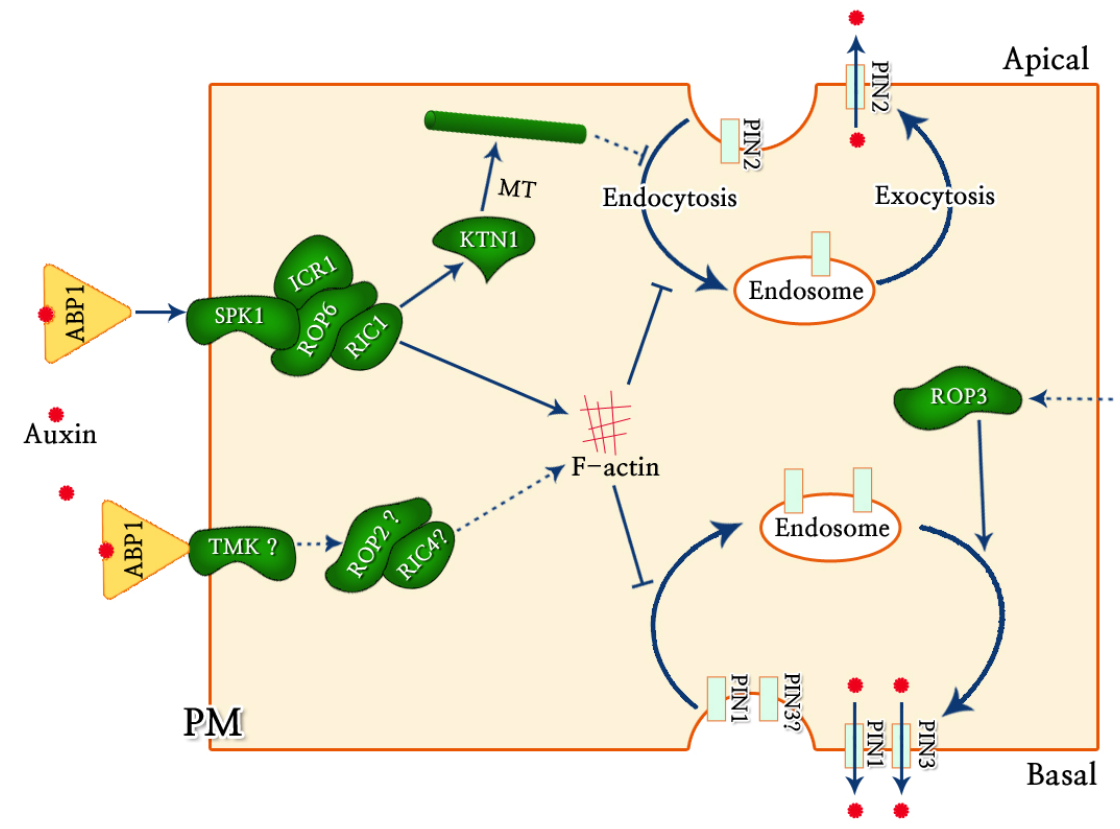

Fig. 2. ABP1 signaling pathway in root cells. In the root, SPK1, after perceiving the ABP1-mediated auxin signal from the apoplast, induces the ROP6-RIC1 signaling pathway, stabilizes the cortical F-actin networks instead of MT and further suppresses the endocytosis of PIN1, PIN2 and possibly other PINs. TMK may also contribute to PIN endocytosis, and ROP3, after receiving a signal from unknown upstream components, promotes PIN1 and PIN3 exocytosis. Dotted lines and question marks indicate potential signaling and signaling components, respectively. the inhibitory effect of $A B P 1$ knockdown lines (SS12S and SS12K), indicating that the ROP6-RIC1 system acts downstream of ABP1 (Chen et al., 2012; reviewed by Ren and Lin, 2015). Although it is possible that SPK1 performs a role similar to TMK in the root, a direct interaction between ABP1 and SPK1 has yet to be determined. Additionally, the role of SPK1 in the ROP3 signaling pathway remains elusive. It is also quite reasonable to suggest that TMK1 might interact with SPK1 to regulate the ROPs (reviewed by Ren and Lin, 2015), and this is worth testing.

A reduced basal-to-apical shift of PIN1 and PIN2 in the root stele and cortex was observed in the Arabidopsis icr1 mutant (Hazak et al., 2010). Reduction in ICR1 transcription could cause aberrant cell division in the embryo at the globular stage (Hazak et al., 2010), downward-folded blades, a short primary root and increased lateral roots (Lavy et al., 2007). Meanwhile, ectopic expression of ICR1 resulted in leaf pavement cells that were not interdigitated and lobed (Lavy et al., 2007), which resembles the abp1 phenotypes (Braun et al., 2008; Chen et al., 2001; Tromas et al., 2009; Xu et al., 2014), spk1, ric1 and pin2 (Lin et al., 2012) and suggests that ICR1 might also have a role in ABP1 signaling. ICR1 has been shown to physically interact with ROP6 and ROP10 and is required for PIN exocytosis (Hazak et al., 2010; Lavy et al., 2007), but the precise function of ICR1 in ABP1 signaling requires further study.

Because TMK was determined to be a transmembrane receptor in ABP1-mediated signaling in the leaf (Xu et al., 2014), SPK1 may also have a role in ABP1 signaling in the leaf. It is also possible that TMK plays the same or a similar role in the root as SPK1. Compared to the wild type Arabidopsis, the tmk mutant has a shorter root and reduced sensitivity to auxin treatment and lateral root induction (Dai et al., 2013), so it resembles the phenotypes of the $A B P 1$ mutants ABP1AS, SS12K and SS12S (Tromas et al., 2009). This suggests a potential role for TMK in root ABP1 signaling, but further studies are required.

\section{ABP1 regulation at the transcriptional level}

Initial research using the abp1-1 plant line and the SS12S/ $S S 12 K$ cell line revealed that ABP1 is related to cell expansion
(Chen et al., 2001) and cell division (David et al., 2007). It was already thought that there should be some overlapping pathway between $\mathrm{ABP} 1$ and traditional $\mathrm{SCF} \mathrm{F}^{\mathrm{TR} 1 / \mathrm{AFB}}$ signaling (Braun et al., 2008; David et al., 2007), but with the availability of inducible $A B P 1$ knockdown Arabidopsis lines (Braun et al., 2008), it was finally possible to examine the influence of $A B P 1$ on genes regulated by the SCF ${ }^{\mathrm{TIR} 1 / \mathrm{AFB}}$ system. The inactivation of ABP1 in SS12K generally reduced the transcription of $A u x / I A A$ genes (Braun et al., 2008), whose expression is known to be regulated by the E3 ubiquitin ligase complex SCF ${ }^{\text {TIR1/AFB }}$ (Mockaitis and Estelle, 2008). Interestingly, compared to the wild type, a subset of the Aux/IAA genes in SS12K showed decreased auxin responsiveness in the shoot (Braun et al., 2008) but increased responsiveness in the root (Tromas et al., 2009), indicating that ABP1 plays a different role in these two organs.

Using a heat-shock-inducible AXR3NT-GUS reporter, functional inactivation of ABP1 in SS12K degraded AXR3NT-GUS as an auxin output sensor, and the level of AXR3NT-GUS increased in a tir/afb mutant background, suggesting that $A B P 1$ is a negative regulator of AUX/IAA degradation. ABP1 seems to increase the stability of AUX/IAA repressors, thus counteracting the SCF ${ }^{\mathrm{TIR} 1 / \mathrm{AFB}}$ pathway (Tromas et al., 2013), and this counteraction could not be influenced by clathrindependent endocytosis inhibitors (ikarugamycin and tyrphostin A23), which indicates that it is independent of ABP1regulated endocytosis (Tromas et al., 2013). Other ABP1 functions, such as cell wall remodeling, also occur via the control of AUX/IAA stability by ABP1 (Paque et al., 2014).

\section{CONCLUSIONS}

ABP1 has been studied for decades, but many questions remain to be answered. ABP1 is predominately localized in the $E R$, and just a small amount can be secreted out (Jones and Herman, 1993; Xu et al., 2014). What is the function of ABP1 within the ER lumen? How does ABP1 escape KDEL retention to get into the apoplast? Unlike other PINs, PIN5 localizes to the ER, possibly regulating the flow of auxin from the cytosol to the ER lumen (Mravec et al., 2009), so would ABP1 regulate PIN5 to modulate intracellular auxin distribution as it does the 
other PINs? Does auxin-free ABP1 also have a function? To date, only one transmembrane protein, TMK, has been identified as an ABP1 receptor (Xu et al., 2014), so are there any other membrane-localized receptor proteins that are required to perform these broad functions? The proteins that functionally overlap with $A B P 1$ remains to be identified.

\section{ACKNOWLEDGMENTS}

This work was supported by Basic Science Research Program (NRF-2013R1A1A2007230) through the National Research Foundation of Korea funded by the Ministry of Education, and funded by the Next-Generation BioGreen 21 Program (SSAC, grant PJ01137901), Rural Development Administration, Republic of Korea. MF was supported by Brain Korea 21 Plus program (BK21+).

\section{REFERENCES}

Barbier-Brygoo, H., Ephritikhine, G., Klämbt, D., Maurel., C, Palme, K., Schell, J., and Guern, J. (1991). Perception of the auxin signal at the plasma membrane of tobacco mesophyll protoplasts. Plant J. 1, 83-93.

Bauly, J.M., Sealy, I.M., Macdonald, H., Brearley, J., Dröge, S., Hillmer, S., Robinson, D.G. Venis, M.A., Blatt, M.R. Lazarus, C.M., et al. (2000). Overexpression of auxin-binding protein enhances the sensitivity of guard cells to auxin. Plant Physiol. 12, 1299-1238.

Bertoša, B., Kojić-Prodić, B., Wade, R.C., and Tomić, S. (2008). Mechanism of auxin interaction with auxin binding protein (ABP1): a molecular dynamics simulation study. Biophys. J. 94, 27-37.

Braun, N., Wyrzykowska, J., Muller, P., David, K., Couch, D., PerrotRechenmann, C., and Fleming, A.J. (2008). Conditional repression of AUXIN BINDING PROTEIN1 reveals that it coordiates cell division and cell expansion during postembryonic shoot development in Arabidopsis and tobacco. Plant Cell 20, 2746-2762.

Brown, J.C., and Jones, A.M. (1994). Mapping the auxin-binding site of auxin-binding protein 1. J. Biol. Chem. 269, 2113621140.

Chen, J.G., Ullah, H., Young, J.C., Sussman, M.R., and Jones, A.M. (2001). ABP1 is required for organized cell elongation and division in Arabidopsis. Genes Dev. 15, 902-911.

Chen, X., Naramoto, S., Robert, S., Tejos, R., Lofke, C., Lin, D., Yang, Z., and Friml, J. (2012). ABP1 and ROP6 GTPase signaling regulate clathrin-mediated endocytosis in Arabidopsis roots. Curr. Biol. 22, 1326-1332.

Chen, X., Grandont, L., Li, H., Hauschild, R., Paque, S., Abuzeineh, A., Rakusová, H., Benkova, E., Perrot-Rechenmann, C., and Friml, J. (2014). Inhibition of cell expansion by rapid ABP1mediated auxin effect on microtubules. Nature 516, 90-93.

Cross, J.W., and Briggs, W.R. (1978). Auxin receptors of maize coleoptile membranes do not have ATPase activity. Plant Physiol. 61, 581-584.

Dai, N., Wang, W., Patterson, S.E., and Bleecker, A.B. (2013). The TMK subfamily of receptor-like kinases in Arabidopsis display an essential role in growth and a reduced sensitivity to auxin. PLoS One 8, e60990.

David, K.M., Couch, D., Braun, N., Brown, S., Grosclaude, J., and Perrot-Rechenmann, C. (2007). The auxin-binding protein 1 is essential for the control of cell cycle. Plant J. 50, 197-206.

Dunwell, J.M., Gibbings, J.G., Mahmood, T., and Naqvi, S.M.S (2008). Germin and germin-like proteins: evolution, structure, and function. Crit. Rev. Plant Sci. 27, 342-375.

de Jager, S.M., Scofield, S., Huntley, R.P., Robinson, A.S., den Boer B.G., and Murray, J.A. (2009). Dissecting regulatory pathways of G1/S control in Arabidopsis: common and distinct targets of CYCD3:1, E2Fa and E2Fc. Plant Mol. Biol. 71, 345-365.

Effendi, Y., Rietz, S., Fischer, U., and Scherer, G.F. (2011). The heterozygous abp1/ABP1 insertional mutant has defects in functions requiring polar auxin transport and in regulation of early auxin-regulated genes. Plant J. 65, 282-294.

Effendi, Y., Jones, A.M., and Scherer, G.F. (2013). AUXIN-BINDING-
PROTEIN1 (ABP1) in phytochrome-B-controlled response. J. Exp. Bot. 64, 5065-5074

Effendi, Y., Ferro, N., Labusch, C., Geisler, M., and Scherer, G.F. (2015). Complementation of the embryo-lethal T-DNA insertion mutant of AUXIN-BINDING PROTEIN 1 (ABP1) with abp1 point mutated versions reveals crosstalk of ABP1 and phytochromes. J. Exp. Bot. 66, 403-418

Enders, T.A., Oh, S., Yang, Z., Montgomery, B.L., and Strader, L.C. (2015). Genome sequencing of Arabidopsis abp1-5 reveals second-site mutations that may affect phenotypes. Plant Cell pii: tpc.15.00214.

Fu, Y., Xu, T., Zhu, L., Wen, M., and Yang, Z. (2009). A ROP GTPase signaling pathway controls cortical microtubule ordering and cell expansion in Arabidopsis. Curr. Biol. 19, 18271832.

Galinha, C., Hofhuis, H., Luijten, M., Willemsen, V., Blilou, I., Heidstra, R., and Scheres, B. (2007). PLETHORA proteins as dose-dependent master regulators of Arabidopsis root development. Nature 449, 1053-1057.

Gao, Y., Zhang, Y., Zhang, D., Dai, X., Estelle, M., and Zhao, Y. (2015). Auxin binding protein 1 (ABP1) is not required for either auxin signaling or Arabidopsis development. Proc. Natl. Acad. Sci. USA 112, 2275-2280.

Grones, P., and Friml., J. (2015). ABP1: finally docking. Mol. Plant. 8 356-358.

Grones, P., Chen, X., Simon, S., Kaufmann, W.A., De Rycke, R., Nodzyński, T., Zažímalová, E., and Friml, J. (2015). Auxinbinding pocket of ABP1 is crucial for its gain-of-function cellular and developmental roles. J. Exp. Bot. pii: erv177.

Habets M.E.J., and Offringa, R. (2015). Auxin Binding Protein 1: a red herring after all? Mol. Plant 8, 1131-1134.

Hazak, O., Bloch, D., Poraty, L., Sternberg, H., Zhang, J., Friml, J., and Yalovsky, S. (2010). A Rho scaffold integrates the secretory system with feedback mechanisms in regulation of auxin distribution. PLOS Biol. 8, e1000282.

Hertel, R., Thomson, K.S., and Russo, V.E.A. (1972). In-vitro auxin binding to particulate cell frations from corn coleoptiles. Planta $107,325-340$

Huang, J.B., Liu, H., Chen, M., Li, X., Wang, M., Yang, Y., Wang, C. Huang, J., Liu, G., Liu, Y., et al. (2014). ROP3 GTPase contributes to polar auxin transport and auxin responses and is important for embryogenesis and seedling growth in Arabidopsis. Plant Cell 26, 3501-3518.

Inohara, N., Shimomura, S., Fukui, T., and Futai, M. (1989). Auxinbinding protein located in the endoplasmic reticulum of maize shoots: Molecular cloning and complete primary structure. Proc. Natl. Acad. Sci. USA 86, 3564-3568.

Jones, AM. (1994). Auxin binding proteins. Annu. Rev. Plant Physiol. Plant Mol. Biol. 45, 393-420.

Jones, A.M., and Venis, M.A. (1989). Photoaffinity labeling of indole3 -acetic acid-binding proteins in maize. Proc. Natl. Acad. Sci. USA 86, 6153-6156.

Jones, A.M., and Herman, E.M. (1993). KDEL-containing auxinbinding protein is secreted to the plasma membrane and cell wall. Plant Physiol. 101, 595-606.

Jones, A.M., Lamerson, P., and Venis, M.A. (1989). Comparison of Site I auxin binding and a 22-kilodalton auxin-binding protein in maize. Planta 179, 409-413.

Jones, A.M., Im, K.H., Savka, M.A., Wu, M.J., DeWitt, N.G., Shillito, R., and Binns, A.N. (1998). Auxin-dependent cell expansion mediated by overexpressed auxin-binding protein 1 . Science 282, 1114-1117.

Lavy, M., Bloch, D., Hazak, O., Gutman, I., Poraty, L., Sorek, N. Sternberg, H., and Yalovsky, S. (2007). A Novel ROP/RAC effector links cell polarity, root-meristem maintenance, and vesicle trafficking. Curr. Biol. 17, 947-952.

Lin, D., Nagawa, S., Chen, J., Cao, L., Chen, X., Xu, T., Li, H., Dhonukshe, P., Yamamuro, C., Friml, J., et al. (2012). A ROP GTPase-dependent auxin signaling pathway regulates the subcellular distriction of PIN2 in Arabidopsis roots. Curr. Biol. 22, 1319-1325

Lin, D., Cao, L., Zhou, Z., Zhu, L., Ehrhardt, D., Yang, Z., and Fu, Y. (2013). Rho GTPase signaling activates microtubule severing to promote microtubule ordering in Arabidopsis. Curr. Biol. 23, 290-297.

Liu, C.M. (2015). AUXIN BINDING PROTEIN 1 (ABP1): a matter of 
fact. J.Integr. Plant Biol. 57, 234-235.

Löbler, M. and Klämbt, D. (1985). Auxin-binding protein from coleoptile membranes of corn (Zea mays L.). I. purification by immunological methods and characterization. J. Biol. Chem. 260, 9848-9853.

Miyawaki, K. N., and Yang, Z. (2014). Extracellular signals and receptor-like kinases regulating ROP GTPases in plants. Front Plant Sci. 5, 449.

Mockaitis, K., and Estelle, M. (2008). Auxin receptors and plant development: a new signaling paradigm. Annu. Rev. Cell Dev. Biol. 24, 55-80.

Mravec, J., Skůpa, P., Bailly, A., Hoyerová, K., Krecek, P., Bielach, A., Petrásek, J., Zhang, J., Gaykova, V., Stierhof, YD., et al. (2009). Subcellular homeostasis of phytohormone auxin is mediated by the ER-localized PIN5 transporter. Nature 459, 1136-1140.

Nagawa, S., and Yang, Z. (2014). The regulation of cell shape formation by ROP-dependent auxin signaling. Plant Cell Wall Patterning and Cell Shape. H. Fukuda. ed. (Hoboken, New Jersey, USA: John wiley \& Sons, Inc.), pp. 164-189.

Nagawa, S., Xu, T., Lin, D., Dhonukshe, P., Zhang, X., Frimi, J., Scheres, B., Fu, Y., and Yang, Z. (2012). ROP GTPasedependent actin microfilaments promote PIN1 polarization by localized inhibition of clathrin-dependent endocytosis. PLoS Biol. 10, e1001299.

Napier, R.M., David, K.M., and Perrot-Rechenmann, C. (2002). A short history of auxin-binding proteins. Plant Mol. Biol. 49, 339348

Palme, K., Hesse, T., Campos, N., Garbers, C., Yanofsky, M.F., and Schell, J. (1992). Molecular analysis of an auxin binding protein gene located on chromosome 4 of Arabidopsis. Plant Cell 4, 193-201.

Paque, S., Mouille, G., Grandont, L., Alabadí, D., Gaertner, C., Goyallon, A., Muller, P., Primard-Brisset, C., Sormani, R., Blázquez, M.A., et al. (2014). AUXIN BINDING PROTEIN1 links cell wall remodeling, auxin signaling and cell expression in Arabidopsis. Plant Cell 26, 280-295.

Paulick, M.G., and Bertozzi, C.R. (2008). The glycosylphosphatidylinositol anchor: a complex membrane-anchoring structure for proteins. Biochem. 47, 6991-7000.

Pelham, H.R. (1989). Control of protein exit from the endoplasmic reticulum. Annu. Rev. Cell Biol. 5, 1-23.

Qiu, J.L. Jilk, R., Marks, M.D., and Szymanski, D.B. (2002). The Arabidopsis SPIKE1 gene is required for normal cell shape control and tissue development. Plant Cell 14, 101-118.

Ren, H., and Lin, D. (2015). ROP GTPase regulation of auxin transport in Arabidopsis. Mol. Plant 8, 193-195.

Rescher, U., Walther, A., Schiebl, C., and Klämbt, D. (1996). In vitro binding affinities of 4-chloro-, 2-methyl-, 4-methyl-, and 4ethylindoleacetic acid to auxin-binding protein 1 (ABP1) correlate with their growth-stimulating activities. J. Plant Growth Re- gul. 15, 1-3

Robert, S., Kleine-Vehn, J., Barbez, E., Sauer, M., Paciorek, T., Baster, P., Vanneste, S., Zhang, J., Simon, S., Čovanová, M., et al. (2010). ABP1 mediates auxin inhibition of clathrindependent endocytosis in Arabidopsis. Cell 143, 111-121.

Shimomura, S. (2006). Identification of a glycosylphosphatidylinostiol-anchored plasma membrane protein interacting with the Cterminus of auxin-binding protein 1: a photoaffinity crosslinking study. Plant Mol. Biol. 60, 663-677.

Shimomura, S., Sotobayashi, T., Futai, M., and Fukui, T. (1986). Purification and properties of an auxin-binding protein from maize shoot membranes. J. Biochem. 99, 1513-1524.

Tejos, R., and Friml, J. (2012). Cell polarity and endocytosis. In Endocytosis in Plants. J Samaj. ed. (Berlin, Germany: Springer-Verlag), pp. 63-80.

Tian, H. Klämbt, D., and Jones, A.M. (1995). Auxin-binding protein 1 does not bind auxin within the endoplasmic reticulum despite this being the predominant subcellular localization for this hormone receptor. J. Biol. Chem. 270, 26962-26969.

Tillmann, U., Viola, G., Kayser, B., Siemeister, G., Hesse, T., Palme, K., Löbler, M., and Klämbt, D. (1989). cDNA clones of the auxin-binding protein from corn coleptiles (Zea mays L.): Isolation and characterization by immunological methods. EMBO J. 8 , 2463-2467.

Tromas, A., Braun, N., Muller, P., Khodus, T., Paponov, I.A., Palme, K., Ljung, K., Lee, J.Y., Benfey, P., Murray, J.A., et al. (2009). The AUXIN BINDING PROTEIN 1 is required for differentia auxin responses mediating root growth. PLoS One 4, e6648.

Tromas, A., Paponov, I., and Perrot-Rechenmann, C. (2010). AUXIN BINDING PROTEIN 1: functional and evolutionary aspects. Trends Plant Sci. 15, 436-446.

Tromas, A., Paque, S., Stierlé, V., Quettier, A.L., Muller, P., Lechner E., Genschik, P., and Perrot-Rechenmann, C. (2013). Auxinbinding protein 1 is a negative regulator of the SCFTIR1/AFB pathway. Nat. Comm. 4, 2496.

Venis, M.A., Napier, R.M., Barbier-Brygoo, H., Maurel, C., PerrotRechenmann, C., and Guern, J. (1992). Antibodies to a peptide from the maize auxin-binding protein have auxin agonist activity. Proc. Natl. Acad. Sci. USA 89, 7208-7212.

Woo, E.J., Marshall, J., Bauly, J., Chen, J.G., Venis, M., Napier, R.M., and Pickersgill, R.W. (2002). Crystal structure of auxinbinding protein 1 in complex with auxin. EMBO J. 21, $2877-$ 2885.

Xu, T., Wen, M., Nagawa, S., Fu, Y., Chen, J.G., Wu, M.J., PerrotRechenmann, C., Frimi, J., Jones, A.M., and Yang, Z. (2010). Cell surface- and Rho GTPase-based auxin signaling controls cellular interdigitation in Arabidopsis. Cell 143, 99-110.

Xu, T., Dai, N., Chen, J., Nagawa, S., Cao, M., Li, H., Zhou, Z., Chen, X., De Rycke, R., Rakusová, H., et al. (2014). Cell surface ABP1-TMK auxin-sensing complex activates ROP GTPase signaling. Science 343, 1025-1028. 